\title{
Implantation of an Endoluminal Prosthesis at the Distal Anastomosis of a Bypass Graft for Abrupt Closure Following Balloon Angioplasty
}

\author{
B.H. Strauss, MD, O. Leborgne, MD, I.K. De Scheerder, MD, Ph.D, \\ and P.W. Serruys, MD, Ph.D \\ A coronary Wallstent ${ }^{\circledR}$ was implanted in a 10-year-old saphenous vein bypass graft fol- \\ lowing a PTCA that was complicated by abrupt closure. Anterograde flow was restored \\ and no myocardial necrosis resulted. One week later, bypass surgery was performed due \\ to a bleeding complication associated with the anticoagulation regimen.
}

Key words: coronary angioplasty, coronary stenting, abrupt closure

\section{INTRODUCTION}

Abrupt closure during angioplasty is usually an unheralded event with potentially catastrophic effects. Several studies have shown that this complication of PTCA occurs in $2-4 \%$ of procedures and is associated with a $43 \%$ myocardial infarction rate and necessitates bypass operation in $1 / 3$ of patients $[1,2]$. Several pathophysiologic processes that contribute to occlusion have been identified, including extensive medial dissection and the formation of intimal flaps, superimposed vasospasm, and possibly thrombus deposition. In this case report we describe successful treatment of abrupt closure in a saphenous vein bypass graft by the placement of a mechanical stent at the junction of the vein graft and native coronary artery.

\section{CASE REPORT}

A 64-year-old man underwent coronary artery bypass grafting to the left anterior descending artery (LAD) and the first diagnonal branch in 1977 for unstable angina pectoris. The patient remained asymptomatic for 10 years when he was admitted to hospital for recurrent anginal episodes associated with ST segment depression at rest. Angiography showed progression of disease in the native vessels, including an occluded LAD as well as two serial narrowings in the distal part of the LAD graft. A PTCA of the graft stenosis was successfully performed and the patient was discharged 1 week later.

Three weeks after discharge, the patient was readmitted for unstable angina. At coronary angiography, an early restenosis of the LAD graft was found, and a second PTCA was attempted (Fig. 1A,B). After inflation with a $2.5 \mathrm{~mm}$ balloon, a luminal irregularity was seen, suggesting an intimal flap or possibly disruption of a friable atherosclerotic plaque. Following redilatation with a $3 \mathrm{~mm}$ balloon, the patient experienced severe chest pain associated with new ST segment elevation. The angiogram now showed a large intraluminal defect (Fig. 1C). Therefore, the decision was taken to immediately implant an endoluminal stent (Wallstent ${ }^{\circledR}$, Medinvent, Lausanne, Switzerland) according to a protocol approved by our Institutional Review Board. The stent was properly deployed at the distal anastomotic site and was visible proximally in the graft and distally in the native LAD (Fig. 1D). The restoration of brisk anterograde flow was accompanied by resolution of the chest pain and electrocardiographic changes.

The anticoagulation regimen was initiated before stenting with the infusion of heparin 10,000 units i.v. and aspirin $250 \mathrm{mg}$ i.v. (which was continued poststenting at a daily oral dose of $250 \mathrm{mg}$ ). During the stent implantation, urokinase 500,000 IU intracoronary and an additional 10,000 units of heparin i.v. were given and followed by a continuous heparin infusion $(30,000$ units/ $24 \mathrm{~h}$ ) that was titrated to maintain an activated partial thromboplastin time between 120 and $180 \mathrm{~s}$. An oral

From the Catheterization Laboratory, Department of Cardiology, Thoraxcenter, Erasmus University, Rotterdam, The Netherlands.

Received April 25, 1990; revision accepted July 24, 1990.

Address reprint requests to P.W. Serruys, Catheterization Laboratory, Thoraxcenter, Erasmus University, P.O. Box 1738, 3000 DR Rotterdam, The Netherlands.

Dr. Strauss is a recipient of a Research Fellowship from the Canadian Heart Foundation. 

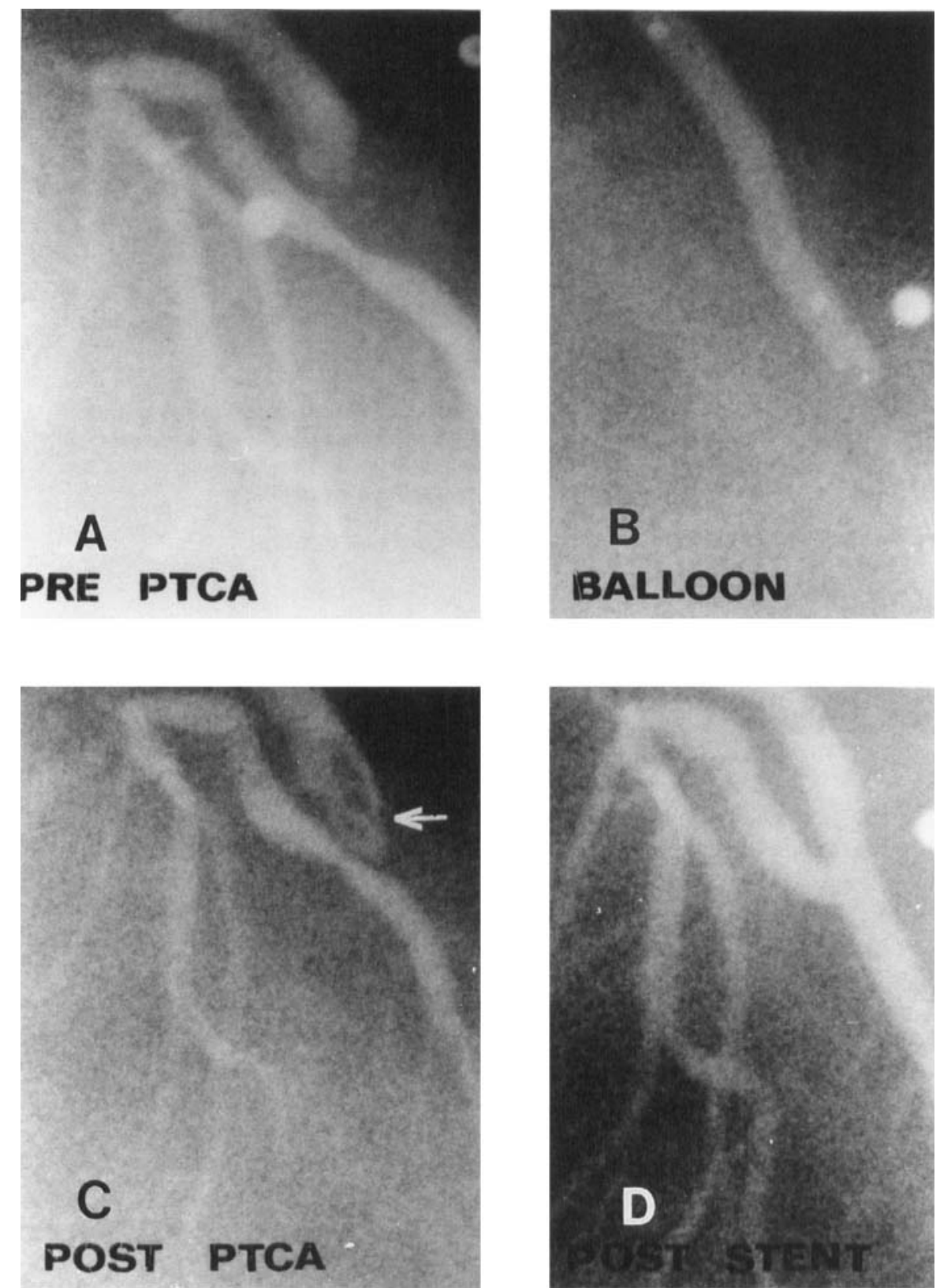

Fig. 1. A: Lesion prior to dilatation. B: During balloon inflation. $C$ : Intermediate result with the intraluminal defect. D: Final result after stenting.

vitamin $\mathrm{K}$ antagonist, acenocoumarol, was prescribed daily starting the day of implantation to maintain the Thrombotest ${ }^{\circledR}$ (Nycomed, Oslo, Norway) between 5\% and $10 \%$ of control activity for 2 consecutive days at which time the heparin was slowly discontinued. The Thrombotest ${ }^{\mathbb{B}}$ is a modified prothrombin time assay that is sensitive for reduced levels of coagulation factors II, VII, and X and the presence of PIVKA (protein induced by vitamin $\mathrm{K}$ absence or antagonists) that result from anticoagulation therapy. An angiogram at $24 \mathrm{~h}$ con- firmed stent patency and absence of the previously observed intraluminal defect (Fig. 2A). Cardiac enzymes were not elevated over the next $72 \mathrm{~h}$, and the patient remained stable.

One week later, while the Thrombotest ${ }^{\circledR 8}$ was within the therapeutic range, the patient suffered an upper gastrointestinal bleed secondary to a Mallory-Weiss tear. The anticoagulation therapy was initially reduced, and later discontinued because of continued bleeding. Subsequently the chest pain and ECG changes recurred and 

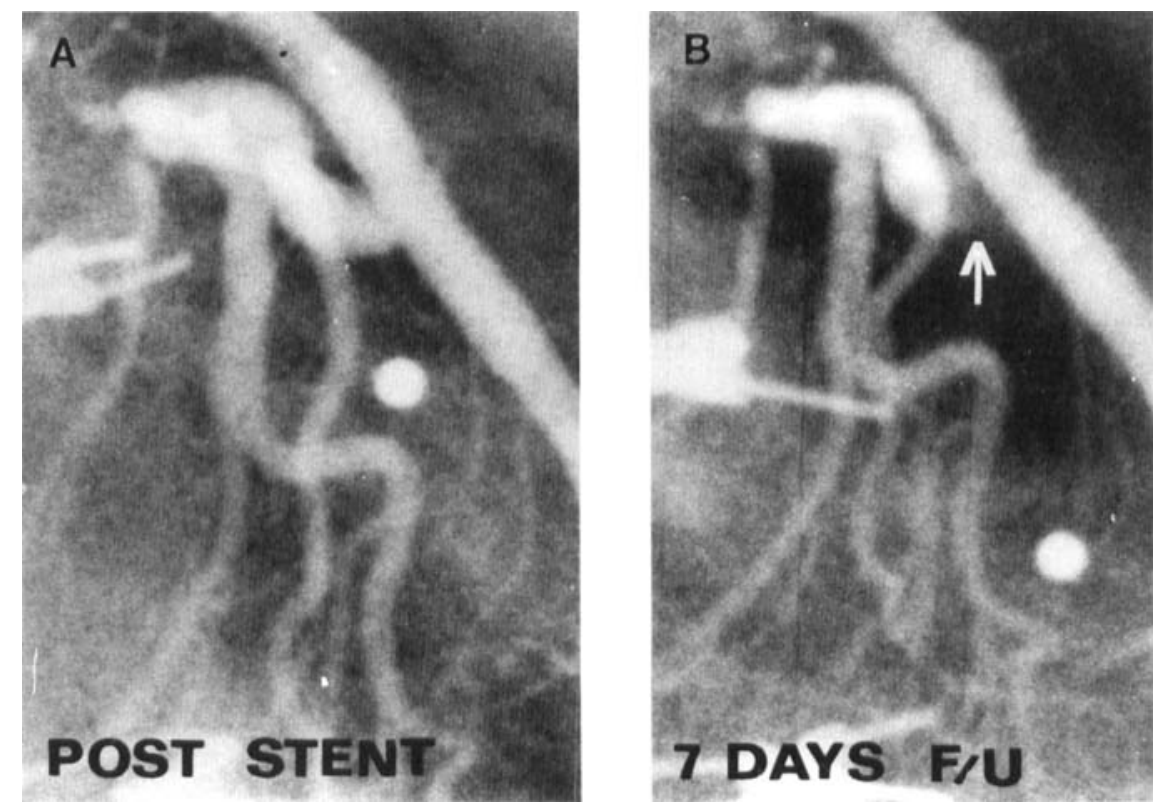

Fig. 2. A: Control coronary angiogram 24 hours after stenting. B: After discontinuing the anticoagulation therapy, a thrombus (see arrow) is visible in the proximal segment of the native LAD.

angiography now showed a thrombus in the proximal segment of the native LAD that was attached to the prosthesis by a small pedicle, although distal flow was maintained (Fig. 2B). Due to the unstable situation and the contraindication to anticoagulation, the patient was sent for bypass surgery from which he recovered uneventfully.

\section{DISCUSSION}

Previous studies have indicated that there is significant atherosclerotic narrowing ( $>50 \%$ diameter stenosis) in about $1 / 3$ of saphenous vein bypass grafts that are patent at 10 years $[3,4]$. Repeat operation is generally less effective and associated with an increased risk compared to the first procedure [5]. PTCA has been investigated as an alternative to surgery for the treatment of saphenous vein graft stenosis. Although primary success rates of PTCA of bypass grafts range from 78 to $93 \%$ [6], it is limited by a high restenosis rate (up to $50 \%$ at the proximal anastomosis) within 6 months of the angioplasty [7] in addition to the acute complications of occlusion and distal embolization. Although the effect of endovascular devices on diminishing the late restenosis rate is currently unknown, this case confirms the finding of one other clinical report (restricted to native vessels) that coronary stenting may be an effective bail-out technique in abrupt closure situation [8].
Saphenous vein bypass grafts in particular have several features that favour the use of stents either as an alternative or an adjunct to PTCA. Atheromatous plaques in saphenous vein bypass grafts often contain an abundant amount of cholesterol crystals and necrotic debris and tend to be softer and more friable than native coronary artery lesions. Pathologic studies have shown that PTCA may induce extensive disruption of these friable plaques, resulting in abrupt closure or distal embolization [9]. This particular stent may act as a splint to contain these protruding lesions as well as limit the elastic recoil that can contribute to abrupt closure and early restenosis. Saphenous vein grafts also tend to be larger than native coronary arteries and better suited to implantation of larger prostheses $(>3 \mathrm{~mm})$ that are less likely to thrombose. The optimal strategy following a bail-out stent (elective surgery or long-term anticoagulation) remains unknown. This case illustrates the hazards of the long-term anticoagulation required with the currently investigated stents. Intensive regimens that include heparin, aspirin, and urokinase during the procedure, followed by at least 6 months of warfarin and aspirin, require careful patient selection and close monitoring. Thrombotic events have occurred in several cases when this schedule has been interrupted, even if only for brief periods of time.

Coronary stenting in saphenous vein bypass grafts has thus far only been investigated with the Medinvent stent [10]. As of February 1990, a total of 156 Wallstents $^{\circledR}$ 
have been implanted in the bypass grafts of 85 patients. Firm clinical indications for implantation of coronary stents in bypass grafts however must await the outcome of randomized trials.

\section{REFERENCES}

I. Simpfendorfer C, Belardi J, Bellamy G, Galan K, Franco I, Hollman J: Frequency, management and follow-up of patients with acute coronary occlusions after percutaneous transluminal coronary angioplasty. Am J Cardiol 59:267-269, 1987.

2. Bredlau CE, Roubin GS, Leimgruber PP, Douglas JS, King SB III, Gruentzig AR: In hospital morbidity and mortality in patients undergoing elective coronary angioplasty. Circulation 72:10441052, 1985.

3. Campeau L, Enjalbert M, Lesperance J et al.: Atherosclerosis and late closure of aortocoronary saphenous vein grafts: Sequential angiographic studies at 2 weeks, 1 year, 5 to 7 years, and 10 to 12 years after surgery. Circulation 68(II):111-117, 1983.

4. Bulkey BH, Hutchins GM: Accelerated "atherosclerosis": A morphologic study of 97 saphenous vein coronary artery bypass grafts. Circulation 55:162-169, 1977.
5. Loop FD, Cosgrove DM: Repeat coronary bypass surgery: Selection of cases, surgical risks, and long term outlook. Mod Concep Cardiovasc Dis 55:31-36, 1986.

6. Kussmaul WG: Percutaneous angioplasty of coronary bypass grafts: an emerging consensus. Cathet Cardiovasc Diag 15:1-4, 1988.

7. Dorros G, Lewin RF, Mathiak LM, et al.: Percutaneous transluminal coronary angioplasty in patients with two or more previous coronary artery bypass grafting operations. Am J Cardiol 61: 1243-147, 1988.

8. Sigwart U, Urban P, Golf S, Kaufmann U, Imbert C, Fischer A, Kappenberger L: Emergency stenting for acute occlusion after coronary balloon angioplasty. Circulation 78:1121-1127, 1988.

9. Saber RS, Edwards WD, Holmes DR, Vliestra RE, Reeder GS: Balloon angioplasty of aortocoronary saphenous vein bypass grafts: A histopathologic study of six grafts from five patients, with emphasis of restenosis and embolic complications. J Am Coll Cardiol 12:1501-1509, 1988.

10. Urban P, Sigwart U, Golf S, Kaufmann U, Sadeghi H, Kappenberger L: Intravascular stenting for stenosis of arotocoronary venous bypass grafts. J Am Coll Cardiol 13:1085-1091, 1989. 